\title{
Explaining Effective Factors on Tourism Industry in Touristic Regions of GuilanProvince (Northern of Iran)
}

\author{
Mohammad Taleghani \\ Department of Industrial Management, Rasht Branch, Islamic Azad University, Rasht, Iran \\ Email:M.Taleghani454@yahoo.com/Email: Taleghani@iaurasht.ac.ir
}

\section{Doi:10.5901/mjss.2016.v7n2s1p486}

\section{Abstract}

\begin{abstract}
Tourism in nature is such economic activity that has been changed into a global industry nowadays. Nowadays development of tourism and entrance of tourist creates high economic, social, cultural and environmental effect on region of accepting tourism. Social-cultural effects of tourism are counted as the most important regards of tourism development in any region. Tourism development has positive social and cultural effect. Therefore the main goal of research is explaining effective factors on development of tourism industry in touristic region of Guilan province. Current research is applied and regarding classification of research based on the way of data collection it is descriptive. Tool of data collection is standard questionnaire that has been designed by Stilidis et al (2013). Sampling method in the research is available improbable sampling method. For considering research hypothesis structural equation modeling has been used. Obtained result of considering research hypothesis denotes effect of local economy development and economic profit, effect of tourism such as economic, cultural and environmental effect on development of tourism industry in Guilan province.
\end{abstract}

Keywords: tourism development, economic effect, SEM, Guilan province.

\section{Introduction}

Tourism industry was firstly applied in an English journal in (1811). At that time this word meant travelling for visiting historical works and natural views for enjoyment. Since then various meaning and definition have been presented through authorities. Here we define tourism that was approved by UN based on international conference of transport and tourism of that organization in Rome:" tourist is the person who travel somewhere other than the place he lives for amusement, visiting places curing, trade, sport or pilgrimage, if his residency isn't less than 24 hours or more than 6 month at least" (Seidaei and HedayatiMoghadam, 2010). High development of tourism industry in recent years has changed it to one of important economic social activities of many countries in the world, as many planners and policy-makers of development know lit as one fundamental basis of constant development. In interpretation of global tourism organization, tourism development is more effective factor against poverty and creating proper field for increasing income of different classes of society, decreasing disease, economic promotion and so improvement of quality of life and social welfare of people especially in less-developed countries(Amini et al, 2011).

Tourism is a phenomenon that deals with daily life of people and develops more every day. Therefore for using this condition and attracting tourist we should benefit different tools such as advertisement (Saei et al, 2010). Nowadays travel industry and tourism are as the greatest and most variable industry in the world and manycountriesconsidered this dynamic industry as the main source of income, employment and growth of private sector and development of infrastructural structure. Tourism is paid attention a lot throughout the world especially in developing countries that other economic forms like production or extraction of natural resources are not affordable(Razavi et al 2013) Degree of sympathy and reliance to each other, tendency to development, degree of future orientation, punctuality, accepting order, taking risk, fractionalizing, and the value that seem for work. Universality against particularism, being active against passiveness, world-oriented, degree of fatalism and lack of fatalism, personal independence, independency, interpretation and perception of a person about changes, degree of person's accounting, optimism and pessimism, order and working conscience, attention to creativity, imprinting, sense of empowerment and many variables of renovation hypothesis have direct relationship with human and interpersonal communication that can be effective at development of tourism industry(Karoubi, 2009). Economic importance and effects of tourism is not hidden for anyone. Tourism is the most important global economy and even the main economic section of many countries. Based on report of GTO during recent 6 decades, tourism has continuous growth and nowadays it is one of the greatest economic sections that have the highest rate of growth among other sections (Khoshkho and Alizadeh, 2013). Tourism development includes different 
aspects like: economic cultural social factors and environmental changes on living style of host society. Also it has useful benefits therefore companies' support of tourism is necessary for consistency of this reality (Lee, 2013).

Perception of residents in touristic regions has potential effect on tourism that leads to more support of this subject. In addition to unique recognition of destination and place attractions and its development it will have perceived effect on residents of regions and provides support for tourist (Stylidis et al, 2014). Nowadays travel and tourism industry was the greatest and most variable industry and many countries seem this dynamic industry as the main source of income, employment, private sector growth and infrastructure development. Tourism throughout the world, Especially in developing countries that other economic forms like production or extraction of natural resources is not affordable is paid attention a lot(Razavi et al, 2013). Based on report of GTO in recent 6 decades, tourism has continuous growth and nowadays it is one of the greatest economic section that has the highest growth rate among other sections (Khoshkho and Alizadeh, 2013).Development of tourism industry in Iran as one strategy y of being released from single-product economy and variety of resources of country's income should be paid attention by planners and policy-makers of the country. Regarding these subjects, current research tries to identify effective factors on growth and development of tourism industry in Guilin province and beside identification of the most effective factors, present necessary strategy for development for se of authorities and private and public sectors of tourism. Regarding mentioned subject's researcher is going to answer this fundamental question:

What are the most effective factors on development of tourism industry in Guilan province and which one has the highest effect?

Therefore the main goal of research is explaining effective factors on development of tourism industry in touristic region of Guilan province. In this way, development of local economy and personal economic profit, tourism effects such as economic, cultural and environmental effects have been considered as research variables.

\section{Theoretical Principles and Research Subjective Literature}

Tourism is counted as one of the most effective ways of economic growth in the world. This industry in recent years has had much effect on economic, social and cultural situation of the world. Creating job, bringing currency, regional balance, helping global peace, helping investment in the area of cultural heritage, optimizing environment, helping optimization of wild life residencies, development of rural area having tourism attraction and preventing migration outside and so on are the advantage of this industry(Hashemi and Mahboobfar, 2013). Growth of tourism industry needs cooperation and agreement of environmental, economic political and social factors in the society. On the other hand growth of tourism industry depends on many factors that can point cases like enhancing standards of living, clean weather, development of transportation, growth and income and leisure time, industrializing tourism and finally identification and meeting needs, demands and interest of tourist with the goal of sectioning market of tourism for presenting goods and proper services (Varesi and Safarabadi, 2014). Tourism as a dynamic industry has many effect on economic, social and cultural situation of the world. In these direction urban residencies as important economic, cultural and service centers have high importance at tourism activities? For achieving goals of constant development regarding social, cultural, economic, environmental and physical dimensions, attitude and systematic and collective analysis is necessary and inevitable (Meshkini et al, 2012).

Tourism is the industry that its development needs identification and sufficient awareness of problems and effective economic, social and cultural factors in any region. Nowadays tourism is changing to one main basis of business economy of the world and many planners remind it as the main basis of human works and as multi-dimensional activity has different positive functions and effects that can point employment, income, attracting currency and strengthening infrastructure. Therefore tourism can be known as one of the most important activity of contemporary human that besides creating great changes in the appearance of earth, changes political, economic, cultural situation and living method of human. Also this category is one important factor in the direction of cultural exchange and familiarity with other nations of various natural and cultural dimensions (Zarayadi and Abdollah, 2014).

Travel and tourism industry is counted as the greatest and most variable industry in the world. Tourism that is identified as a social-cultural phenomenon is called the greatest movement and placement of human. Its increasing growth caused many authorities call 20th century as the tourism century. This industry affects economic, social and cultural area like external exchanges, income, and employment-prices-distribution of incomes, migration, and division of work, tradition and arts. Nowadays importance of tourism is to the degree that economically and regarding occupation can be counted as economic force of any country. Tourism has many advantages and can be important source for employment. Tourism is the activity that beside economic and employment advantage, has many social and cultural effects. By developing tourism we can cause level of welfare of local communities' life but attracting tourist is counted as 
one important competitive factor and the best index for guaranteeing growth of future profit and degree of tourist satisfaction is counted as important criteria for assessing quality of work. As degree of tourist satisfaction and normal expectation of tourist is supplied the degree of attracting tourist and development of tourism will be realized (Hezarjaribi and najafi, 2012).

Tourism industry is one of the most thriving economic activity in the world and has importance at economic and social development of countries that economist called it invisible export. At industrial countries tourism industry causes variety of income and decreasing incoordination in economy and in developing countries, it is an opportunity for export, producing currency and creating job. Tourism plays important role at economy of societies and exact identification of market is key factor if its development. On the one hand although tourism is an international activity, many people and organizations in local or national market are busy in this section and so internal tourism has extensive location at national economy. Identification and introducing features, attraction and potential powers of attractions are fundamental basis of tourism and is acriterion for determining capacity of accepting tourism, planning of market development and marketing management. Generally tourism resources regarding place-special distribution and specific features due to historical records, existence of valuable and unique factors, visual attraction, and aspects of purity, being natural or cultural and so on respond specific section of market (Bozari et al, 2013). Development of tourism depends on economic system of capitalism at the first step. Capitalism system based on its innate reason (storage of capital for more investment or the same profit and investing that profit for achieving more profit) should be fallowing new markets for its products to be able to reproduce itself and continue life. However because system of capitalism based on its internal reason, has crisis inside, tries to avoid periods of this crisis(like crisis over production, crisis of inflation recession) and solve pioneering crisis temporarily. Therefore capitalism system needs geographical development and variety and development of consumption. On the other hand a new approach entitled as "welfare of government" entered capitalism economy. In fact rising of government of welfare caused formation of relative welfare among people in western countries and created second goal of capitalism that is development of consumption and variety in consumption. So by increasing relative welfare and creating variety in consumption number of tourist increases (Mousaei et al, 2012).

Tourism affects economic growth indirectly' because it shows dynamic effect at the whole economy in the form of spillovers ${ }^{1}$ and or other externalities ${ }^{2}$. In this form that if tourism promote due to high interaction with other economic activities, other economic activities that present to that good or service or consume that product will move by it. That is tourism can act as a motor for economic growth that moves other activities forward. On the other hand, economic growth is effective on tourism development. Economic growth by developing facilities and tourism infrastructure such as development of transportation of ways, development

ITC ${ }^{3}$ development of electronic money, development of residential places, restaurants and hotels, development of public health and also development of recreational facilities and welfare affairs, cause development of tourism industry(Tayebi et al, 2007). Perceived situation of local economy considers viewpoint and attitude of residents from three key and important local economies that is occupation, level of life and environment of work. Agreements of these aspects showed that residents have relationship with local economy. Some studies assessed economic profit of residents about different methods of measurement that includes employment and personal or family occupation in tourism. Apart from these methods perceived personal economic profit of tourism have been considers criteria of powerful measurement (stylidis\&Terzidou, 2013).

Tourism has much effect on economic growth of small industries dependent to tourism. Also it has positive effect on increasing economic growth through different channels in long-term. Because tourism cause profitability of economic development through channel of entering goods and currency exchanges and also causes capital process and goods (Schubert et al, 20110. Tourism is counted as a key section for short-term and long-term economic growth. Tourism because increase of economic activity and this increase I activity is favorable and efficient normally and has positive effect on economic activities and improvement of small and big economic process (chou, 2013). Tourism can affect other economic industries directly and indirectly and leads to production of employment and income. Tourism caused utilization of positive economy in national scale and finally it is an important factor at distributing technical knowledge, stimulating research and development and collecting human capital. Tourism leads to external exchange of currency among countries. It increases of market demand and effectiveness and economic utilization for goods and services. It encourages competition and has positive effect at the level of price of goods and services and leads to improvement of life especially in small countries and their local economy (Schubert et al, 2011).

\footnotetext{
${ }^{1}$ s spillovers

2 externalities

${ }^{3}$ Information and communication technology
} 
Social cultural effect of tourism are methods in which tourism creates changes in systems of value, behavior of people, relations of families, collective living style, traditional customs and social organizations and is counted as the most important regards of tourism development in any region, although measuring these works is more difficult than economic and environmental works. These works can determine fate in countries that are severely traditional socially and economically (Seidaei and Rostami, 2012). Tourism promotion in any geographical place beside positive and negative economic, social consequences has environmental effect that in case of continuing it can lead to in compensational consequences. Nowadays activity of human and its effect on environment has dimensions that the area of penetration of these pollution and destruction of environment hasn't been limited to a specific point of the world; these problems have occupied the most places in the world. Tourism can be accompanied by fundamental support for a geographical region if its environmental indices are observed. That is systematic analysis about environment and economic and social planning should be done in detail and by special regards to different kinds of tourism development (Azmi et al, 2011).

\section{Research Conceptual Model}

Theoretical framework is a pattern based on theoretic relations between effective factors on research subject, in these model variables of development of local economy and personal economic profit, tourism effects such as economic, cultural and environmental effects have been considered as independent variables and tourism development has been considered as dependent variable. Research model was based on research model of stylidisand relations between research variable has been shown in the following table:

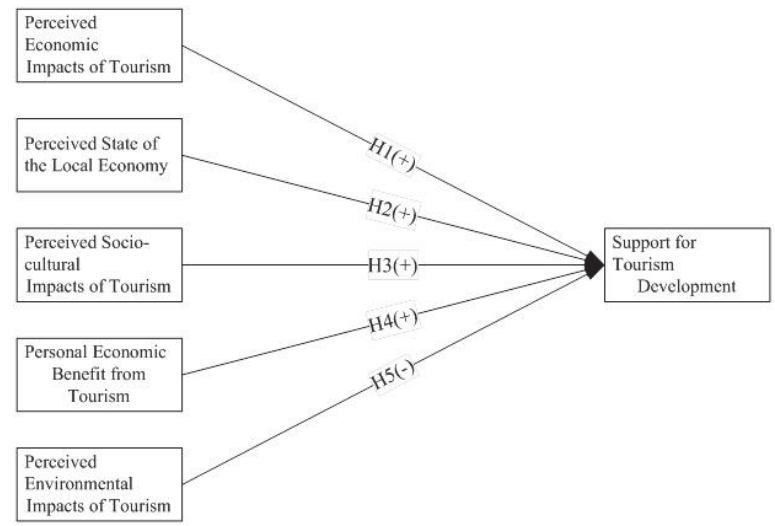

Figure (1): Modified model taken from (stylidis and Terzidou, 2013).

Based on research conceptual model hypothesis of research are written as below:

$\mathrm{H}_{1}$ : economic of tourism industry has positive effect on development of this industry in Guilan province.

$\mathrm{H}_{2}$ : local economy development has positive effect on development of this industry in Guilan province.

$\mathrm{H}_{3}$ : cultural-social effects of tourism have positive effect on development of this industry in Guilan province.

$\mathrm{H}^{4}$ : personal economy profit has positive effect on tourism industry in Guilan province.

$\mathrm{H}_{5}$ : environmental effect of tourism industry has positive effect on development of this industry in Guilan province.

\section{Methodology}

Based on method Current research is descriptive and briefly it can be said that this research is descriptive and surveyingcorrelation type. Also, this research regarding goal is applied. Statistical society of research was all residents of touristic regions in Guilan province. Sampling method in the research is cluster and available improbable sampling type. In this form that firstly touristic regions of Guilan province were identified and then some samples were chosen in the form of available improbable and their number was 332 people. All items were coded through 5 -item scale of likert spectrum. Due to probability of lack of returning some questionnaires, 360 questionnaires were distributed that 343 ones were collected. Regarding that return rate of questionnaire was higher than $90 \%$, so 343 questionnaires were analyzed. Research 
questionnaire was standard one that its questions were designed by Stylidis and Terzidou(2013) that after translation and localizing the were used in this research. Information related to questions of questionnaire regarding number of questions and resources has been mentioned in table (1):

Table (1): information of research questionnaire

\begin{tabular}{|l|c|l|}
\hline Source & Number of questions & Variables of model \\
\hline Stylidis and trezidou) 2013( & 3 & Local economy development \\
\hline Stylidis and trezidou)2013( & 3 & Personal economic profit \\
\hline Stylidis and trezidou)2013( & 4 & Economic effect of tourism industry \\
\hline Stylidis and trezidou)2013( & 4 & Cultural social effect of tourism industry \\
\hline Stylidis and trezidou)2013( & 4 & Environmental effect of tourism industry \\
\hline Stylidis and trezidou)2013( & 3 & Development of tourism industry \\
\hline
\end{tabular}

In this research content validity and reliability was used for considering tools of data collection. For considering content validity the viewpoint of respected professors and some of professors were used. After designing and writing questionnaire and confirming it by professors and specialties researcher was going to determine the degree of reliability of questionnaire. Therefore a primary simple including 30 questions were pre-tested. Amount of cronbach alpha for all variables of research and also amount of this coefficient for the whole questionnaire was over 0.7. Exact amount of this coefficient has been mentioned in table (2).

Table (2): Reliability coefficient of variables of questionnaire

\begin{tabular}{|c|l|}
\hline Amount of cronbach alpha & Variables of model \\
\hline 0.895 & Local economy development \\
\hline 0.714 & Personal economic profit \\
\hline 0.736 & Economic effect of tourism industry \\
\hline 0.802 & Cultural social effect of tourism industry \\
\hline 0.829 & Environmental effect of tourism industry \\
\hline 0.715 & Development of tourism industry \\
\hline 0.813 & The whole questionnaire \\
\hline
\end{tabular}

\section{Kolmogorov-Smirnov Test}

In this section for considering normality of research variables Kolmogorov-Smirnov test has been used. Regarding that sig of all variables of research is bigger than $5 \%$ so normal distribution of data of all variables of research fallows normal distribution.

Table (3): Kolmogorov-Smirnov test for testing normality of data

\begin{tabular}{|l|c|c|}
\hline & Number of samples & Sig \\
\hline Local economy development & 332 & $\mathbf{0 . 0 8 9}$ \\
\hline Personal economic profit & 332 & $\mathbf{0 . 0 6 1}$ \\
\hline Economic effect of tourism industry & 332 & $\mathbf{0 . 0 5 9}$ \\
\hline Cultural social effect of tourism industry & 332 & $\mathbf{0 . 1 1 2}$ \\
\hline Environmental effect of tourism industry & 332 & $\mathbf{0 . 0 7 6}$ \\
\hline Development of tourism industry & 332 & $\mathbf{0 . 0 9 2}$ \\
\hline
\end{tabular}

\section{Confirming Factor Analysis}

In his section two important output of Lisrel model that is model in standard solution mode and meaningfulness of coefficient are presented. 


\section{Model in Standard Solution ${ }^{4}$ Mode}

Regarding fig (2) we can observe factor load of each question of research. Amount of determination coefficient is a number between 0-1 that as it closes 1, amount of explaining variance becomes more.

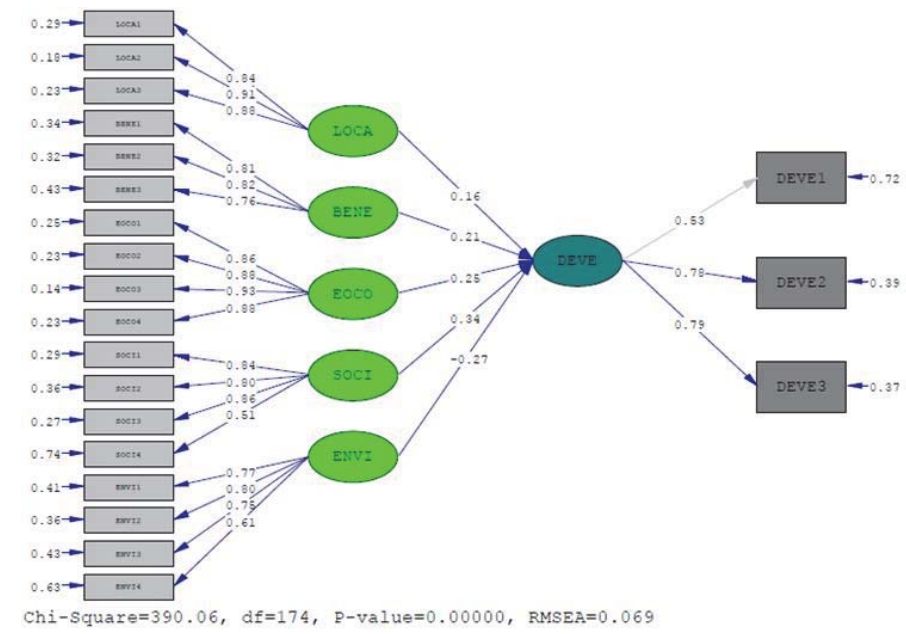

Figure (2): Research model in standard solution mode

\section{Model in T-value Mode}

Fig (3) shows meaningfulness of coefficients and obtained parameters of model that all obtained coefficients have become meaningful. Basis of confirming or rejecting hypothesis of research is considering model in meaningfulness mode. Regarding mentioned cases all hypothesis of research are approved.

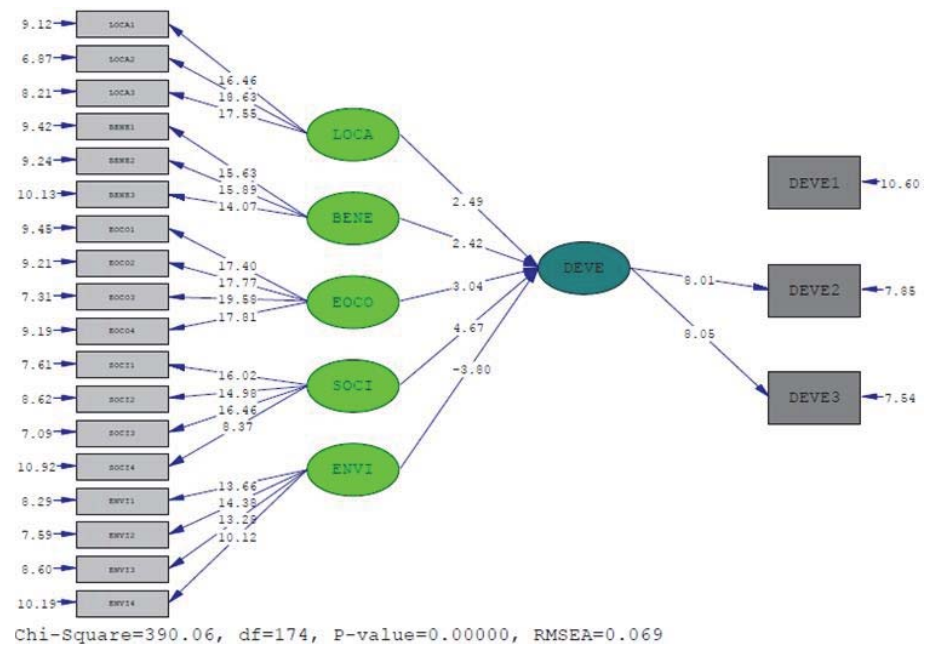

Figure (3): research model in meaningfulness coefficient mode 
In table 4 result of considering research hypothesis have been mentioned briefly:

Table (4): considering result of research hypothesis

\begin{tabular}{|c|c|c|c|c|}
\hline Conclusion & Sig & Standard coefficient & Research hypothesis \\
\hline Accept & 2.49 & 0.16 & Economic effect of tourism industry on development of this industry has positive effect. \\
\hline Accept & 2.42 & 0.21 & development of local economy on development of this industry has positive effect \\
\hline Accept & 3.04 & 0.25 & Cultural-social effect of tourism industry on development of this industry has positive effect \\
\hline Accept & 4.67 & 0.34 & personal economic profit on development of this industry has positive effect \\
\hline Accept & -3.8 & -0.27 & environmental effect of tourism industry on development of this industry has negative effect \\
\hline
\end{tabular}

\section{Fit Indices of Research Model}

In table (5) indices related to model fitting has been mentioned by its favorable amount. In comparing amount of research model and favorable amount this subject becomes clear, research model is located in favorable mode regarding all indices.

Table (5): Fit indices of research model

\begin{tabular}{|c|c|c|c|c|c|c|c|c|l|}
\hline IFI & CFI & NNFI & NFI & GFI & RFI & AGFI & RMSEA & $\mathbf{x}^{2} / \mathbf{d f}$ & \\
\hline $0.9 \geq$ & $0.9 \geq$ & $0.9 \geq$ & $0.9 \geq$ & $0.9 \geq$ & $0.8 \geq$ & $0.8 \geq$ & $0.08 \leq$ & $3 \leq$ & Standard amount \\
\hline 0.97 & 0.97 & 0.97 & 0.95 & 0.90 & 0.94 & 0.84 & 0.069 & 2.241 & Model amount \\
\hline
\end{tabular}

\section{Conclusion and Suggestion}

Nowadays tourism is reminded as one of the most important income source and economic output. Iran beside having many capacities and capabilities for development of tourism industry, even among the first 50 countries in the world don't have location and generally could prepare proper place for itself in beneficial mark. Guilan province is one of the most significant province of the country in the field of number of historical works that reconstructing changing and manipulation of extensive part of these works over years, life and also it changed dynamic and development of its texture to a set of historical works that is unique not only at the country but also in the world. For example Masouleh city is as the second tourism region in the world that has saved its texture since the beginning of construction up to now. Nowadays significant and attractive tourism buildings has destroyed over time and by the effect of factors such as weakness of equipment's and facilities, and lack of proper access and forces related organizations to reconstructing and optimizing these constructions that it can cause return of life to historical texture but by looking at the statistics of budget of other provinces it is distinguished that subject of tourism hasn't been paid attention by authorities and as it is compatible it couldn't achieve its real place and credit about attracting tourist. Therefore researcher in the direction of result of research has presented suggestions in the fallowing form:

1- Regarding effective role of tourism at economy of the Guilan province, more attention to this industry is necessary. In this field it is suggested pay more attention to existing resources of tourism by national and international value. Variety of attractions in Guilan province caused existing little budget distributed between many attractions and so concentration on strengthening national and international attraction can have more effectiveness.

2- Regarding lack of compatible and necessary presence of private sector about tourism that part of it is inflectional due to economic conditions and being low output, development of tourism with concentration of private sector is advice. Preparing condition of enter of private sector in the field of tourism often happens through advertisement, supply, development and improvement of infrastructure, giving low-price facilities, reliance of introducing opportunities and projects, investment about tourism with technical, financial and economic analysis.

3- Improvement of situation of advertisement and informing about fields that Guilan province has potential of attracting tourist can lead to attracting more visitors. In this field using facilities and updated tools of advertisement and informing causes more identification of attractions in Guilan province that will be field of attracting more tourist. 
4- At the end it is necessary to consider the point that this research like any other research isn't lack of limitation. However one of the most important limitations of research was testing research model in geographical area of Guilan province, so it is suggested in future research model tested in other touristic provinces.

\section{References}

Amini, Mohammadtaghi' Abasi, Mohammadreza, Pirali, Alireza(2010). Writing strategy of development of tourism industry of free region of Gheshm from Swat model, management and development process, 76,156-169

Azmi aeizh, ImaniBahram, KhaniFazileh(2011), effects of tourism activity on environment(case study: BilehDoroghilage), scientific research quarterly of new attitudes in human geography, 3,3,13-25

Bozari, Sima, Khaligheh, Ebrahim, Babakinejad, Mojtaba(2013), explaining the role of great market of Tehran at turban tourism development, geographical quarterly of land, 10, 38, 63-80

Chou Ming Che, (2013), "Does tourism development promote economic growth in transition countries? A panel data analysis", Economic Modeling, 33, 226-232.

Hashemi, Seyedsaeid, Mahboubfar, Mohammadreza(2013). Strategic planning of tourism development of Kashan, tourism quarterly of university of science and culture, 1-26

Hezar Jaribi, Jafar, Najafi, MalekMohamad(2012) considering demography of effective factors on tourism development in Iran, geography and environmental planning, 23, 47, 133-146

Karoubi,Mehdi(2009). Considering the role of human communication in development of tourism ndustry, management science quarterly of Iran, 4, 13,101-130

Khoshkho Mohannadhosein, AlizadehValiolah(2013),"tourism economy", tourism quarterly of science and culture university, 4,17-32

Lee Tsung Hung, (2013), "Influence analysis of community resident support for sustainable tourism development", Tourism Management, 34, 37-46.

Meshkini, Abolfazl, Soltanzadeh, Akbar, Rahmati, Akbar and Zareiyousef(2012). Opportunities and problems of development of tourism industry of Maragheh city, economy and urban management quarterly,1, 83-101

Mousaei, MeisamMousaei, Hashemi, Somayeh, Ebrahimi, Mitra(2012). Considering sociology of constant development of tourism in Iran' barriers, challenges, strategies, especially quarterly of social science of Islamic azad university -Shoshtatbranch, 6, 16. 2550

Razavi Mohammad Hossein, Hoseini, SeyedEmad, KhajehpourAkram(2013)'considering effective natural attractions on sport tourism development of Mazandaran province, research letter of sport management and motion behavior, 17, 15-30

Schubert Stefan Franz, Brida Juan Gabriel, RissoWistonAdrián, (2011), "The impacts of international tourism demand on economic growth of small economies dependent on tourism", Tourism Management, 32, 377e385.

Sedaei SeyedEskandar, HedayatiMoghadam Zahra, "role of security at tourism development" specialty quarterly of social science at Islamic azad university of shoshtar branch, 2010, 4,8,97-110

StylidisDimitrios, BiranAvital, Sit Jason, Szivas Edith, (2014), "Residents' support for tourism development: The role of residents 'place image and perceived tourism impacts", Tourism Management, 45, 260-274.

StylidisDimitrios, TerzidouMatina, (2013), "Tourism and the economic crisis in Kavala, Greece", Annals of Tourism Research, 1-17.

Tayebi Seyedkomeil, BabakiRooholah, Jabari Amir,(2007), " considering the relationship of tourism development and economic growth in Iran(1999-2004), human and social science research letter<, economy specific >>,7,26,83-110

Varesi, Hamid, and safarabadi, Azam(2014). Role of social factors of tourism on urban tourism development, urban sociological studies, 4, 12, 1-1-128

Zarabadi, Zahra Sadat, and abdollah, Bahar(2014). Assessing effective factors at development of tourism industry of free region of Chabahar by benefiting Analyzing network process method, scientific-research journal of architecture and urbanization congress of Iran, 6,37-48 